\title{
Living donor liver transplantation
}

\section{AV SRINIVAS}

House No 167/A, Sripuram Colony, Malakpet, Hyderabad, 500036 INDIA e-mail; av_srinu@yahoo.com

There was some debate within the editorial board about the appropriateness of carrying the following exchange in an ethics journal. At one level it is a'complaint'from a patient's relative and an institution's defence of the allegations. However at another level it raises larger issues relevant to contemporary ethics.

The field of organ transplantation is no stranger to ethical controversy. A particularly complex issue involves living related transplantation where a healthy donor is at some risk, including the risk of death. In other words in an attempt to save one life two lives can be lost. It is obvious that such a potentially dangerous situation needs the highest level of informed consent. And if things do go wrong there must be a sound and transparent mechanism of dealing with the situation.

This journal has previously carried an editorial on the issue of living related liver transplantation.

This unfortunate incident also points to the potential danger of an ir.creasing trend, in the globalised world, of foreign doctors performing procedures and flying back leaving their local counterparts to face the complications.

Hence we finally decided to put before you the story of a family bravely facing a tragedy of immense proportions. It also highlights the problems of high technology medicine where high-risk, complicated and costly procedures are marketed and performed with a promise of cure.

Editors

Mr AV Srinivas wrote to IJME describing his parents' experiences. Mr Srinivas' father was diagnosed as suffering from liver failure and advised a liver transplant. The transplant was carried out in April 2003, in Global Hospital, a private hospital in Hyderabad. The donor was Mr Srinivas' mother. The transplant was done by a team of surgeons headed by Dr Nigel Heaton and Dr Paolo Mueisan from King's College Hospital, UK. The Global Hospital team included Dr Kancherla Ravindranath, managing director of Global Hospitals and head of its department of surgical gastroenterology, $\mathrm{Dr}$ Dharmesh Kapoor, hepatologist, Dr PBN Gopal, anaestheologist and intensivist, Mrs Lalitha Raghuram, chief liver transplant coordinator, and the support staff.

Mr Srinivas' father died within two weeks of the transplant, in the hospital ICU. His mother suffered a cardiac arrest within 48 hours of the surgery and has been in a persistent vegetative state since.

Mr Srinivas feels strongly that the hospital and staff behaved unethically in promoting adult-to-adult live transplants without the necessary experience. The hospital and staff did not indicate that adult-to-adult live liver transplants are more risky than those from adults to children. Further, Mr Srinivas states that he was not made aware that this was the first adult-to-adult live donor liver transplant in India. Finally, he notes adult-to-adult live donor liver transplants are not permitted within the UKNational Health Service (NHS) because of the risks to the donor. Kings College, with which Dr Nigel Heaton and Dr Paolo Mueisan are associated, is part of the NHS. Such transplants are done in the UK only in the private sector, mostly on foreign nationals.

Mr Srinivas provided IJME with replies to letters he wrote to the $B B C$, the UK General Medical Council and Professor Roger Williams, director of the Institute of Hepatology, Royal Free and University College Medical School. The BBC's reply notes that it had a policy of not releasing untransmitted footage but would consider his request if he would indicate what was contained in the footage that might be of his interest. The GMC replied that his complaint had been forwarded to Drs Heaton and Muiesan. Professor Williams indicated that adult-to-adult live donor transplants are not done in the UK under the NHS, but UK doctors do make this available in the private sector, mostly to people from outside the UK. He added that as a person working with the doctors named, he could not comment further but suggested the names of others who could.

The following account is based on Mr Srinivas'statement as well as some documents sent by him.

My father's health problem-cirrhosis of the liver-- was identified in late 2001. Over 2002, we visited Dr Nageshwar Reddy at the Asian Institute of Gastroenterology. Dr Reddy spoke about the transplant option but said the success rate was not good in India.

Towards the end of 2002, we saw media reports that experienced liver transplant surgeons from King's College Hospital, UK, would be doing liver transplants at Global Hospital, Hyderabad. in December 2002 we visited Global Hospital for the first consultation with Dr Dharmesh Kapoor of Global Hospital, who told us to continue the previous medication with a few changes. We were told that Dr Mohammed Rela, a liver transplant surgeon from King's College, UK, would be visiting Global Hospitals and took an appointment with him. Dr Rela examined my father and also went through his medical records. He said the only option was a liver transplant, and that he was a suitable candidate. Dr Kapoor and Dr Rela said many transplants were being done in the West and that in the UK they had a good success rate. 
In early March 2003, we consulted Dr Hector Vilca Melendez, also of King's College, during his visit to Global hospital. This was shortly after the media reported on the first liver transplant done there, by Dr Melendez. Dr Melendez went through the medical history and told us transplant was possible, and described the success rate in the UK. We discussed the matter again with $\mathrm{Dr}$ Dharmesh Kapoor and on his advice my father went for preoperative investigations for which we paid Rs 95,000 .

On March 28, 2003, Mrs Lalitha Raghuram, chief transplant coordinator in Global Hospital who also heads the Hyderabad branch of the MOHAN foundation (an NGO promoting organ donation/ harvesting), called us to say there was a prospective (cadaver) donor available. She asked us to make a deposit of Rs 10 lakh immediately, and indicated that the surgery could be done any time as the surgeon from the UK was in Hyderabad. She also said that unless the patient was operated upon immediately, his condition could worsen and he could become unfit for surgery. We borrowed the money from various people and deposited it but then we did not hear anything more on the matter. Some days later, we were informed there was a cadaver liver available in Chennai. We were told to decide within half an hour if we could pay Rs 7 lakh for the chartered flight from there. We said we could not afford it.

In the meantime my father's health deteriorated and we took him back to the hospital. This was when we were first advised to consider a live donor transplant, from a family member. My mother was counselled. My parents did not consider my brother or me as potential donors, I suppose because of our career and marriage future.

I do not have any documents on the informed consent process. Family members were also spoken to, but I do not recollect much counselting. They explained that the donor's liver would grow back to normal size within two weeks, and she would be back to her normal self in 4-6 weeks. They did not describe any risks. They did not mention the difference in risk between an adultchild live liver transplant and an adult-adult live liver transplant. They used the term 'live liver transplant' only.

They also said the search for a cadaver liver would continue and if it was found the live donor transplant would be cancelled. We were also assured that we would not be charged for the donor's expenses and my mother was asked to undergo investigations. My mother was hesitant but she saw this as my father's only hope. She was found to be fit for the transplant.

The surgeons were Dr Nigel Heaton and Dr Paolo Mueisan of King's Hospital,UK. Dr Heaton checked on my mother before the surgery. He said it would be major surgery for the donor - this was the first time we heard the word - but that everything was fine. He also said he had done about 55 live liver transplants and none of the recipients had died. The doctors also said my father was in good shape for surgery and would survive the operation. No one used the term 'adult to adult live donor liver transplant'. They described it as 'live liver transplant' We did not know that there are different success rates - and risks -- for partial liver transplants from live donors and total liver transplants from cadavers. Dad's was the third liver transplant at Global Hospital; the previous two were cadaver transplants.

In the early hours of April 22,2003, both our parents went into the operation theatre. We were told the surgery went well. it took 22 hours. Then on April 24, within 48 hours of the surgery, my mother had a cardiac arrest in the ICU. By the time they got her heart beating again, she had suffered brain damage. We believe this happened because a delay in resuscitation led to irreversible brain damage. They kept telling us that she would recover, but the extent of damage could not be known until she regained consciousness. It is now more than two years.

My father died in the ICU within two weeks of surgery. The death report, signed by Dr PBN Gopal, anaesthetist, states that the cause of death was multi-organ failure due to fungal septicaemia. We believe that he was operated upon when he was unfit for surgery.

A team from the BBC had accompanied the UK doctors. They interviewed my parents before the surgery, they videotaped the surgery and also interviewed the family after the surgery. The hospital and BBC termed it the first Indian related live donor liver transplant (my parents are related). The BBC team left a few hours after my mother went into coma.

The UK doctors are aware that my father died within two weeks of the transplant and that my mother went into a coma. One of them was there when my father passed away. Neither of them has called back to ask how she is.

We had been told that the total cost would be Rs 12 lakh. In March 2003 , we paid Rs 10 lakh and another Rs 95,000 in pre-operative tests for my father. The doctors indicated that they would not charge for the donor's expenses. When she was being taken into the operating theatre we were asked to sign a form committing to pay Rs 23 lakh, including donor expenses. We objected but Mrs Lalitha Raghuram advised us to sign so the surgery could proceed, and this would be settled during the final billing. Even as our parents lay in a coma we were repeatedly pressurised for the payment, including with threats that medication would have to stop. Later they indicated that they would bear the cost of treating my mother. In January 2005 they sent us a bill of Rs 45 lakh, towards the cost of mom's treatment for the previous 20 months.

Did the Global Hospital have staff skilled and experienced to perform the surgery and advise the patient's family on whether the patient is suited for the transplant? I believe that they advocated a complicated and expensive surgery without giving the family sufficient information on the risks associated with the transplant, especially for adult donors.

In the US, there are regulations and some action is taken when things go wrong. Should hospitals in India here not have the same level of scrutiny? 